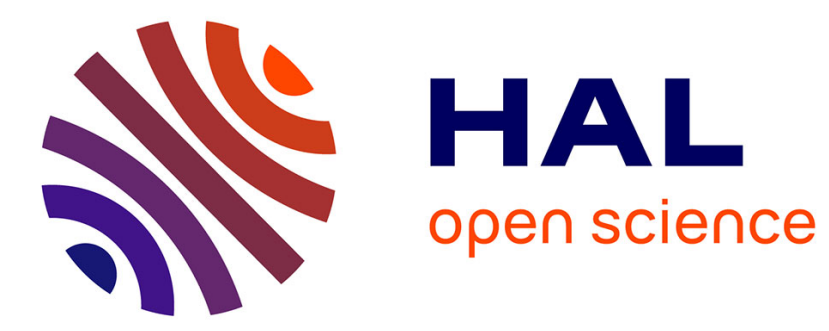

\title{
Preparation and characterization of carnauba wax nanostructured lipid carriers containing benzophenone-3
}

Suenia de Paiva Lacerda, N. N. P. Cerize, Maria-Inês Ré

\section{To cite this version:}

Suenia de Paiva Lacerda, N. N. P. Cerize, Maria-Inês Ré. Preparation and characterization of carnauba wax nanostructured lipid carriers containing benzophenone-3. International Journal of Cosmetic Science, 2011, 33 (4), pp.312-321. 10.1111/j.1468-2494.2010.00626.x . hal-01717486

\section{HAL Id: hal-01717486 \\ https://hal.science/hal-01717486}

Submitted on 28 May 2018

HAL is a multi-disciplinary open access archive for the deposit and dissemination of scientific research documents, whether they are published or not. The documents may come from teaching and research institutions in France or abroad, or from public or private research centers.
L'archive ouverte pluridisciplinaire $\mathbf{H A L}$, est destinée au dépôt et à la diffusion de documents scientifiques de niveau recherche, publiés ou non, émanant des établissements d'enseignement et de recherche français ou étrangers, des laboratoires publics ou privés. 


\title{
Preparation and characterization of carnauba wax nanostructured lipid carriers containing benzophenone-3
}

\author{
S. P. Lacerda*, N. N. P. Cerize† and M. I. Ré†, † \\ *Federal University of Pernambuco (UFPE)/Post-Graduate program in Pharmacy, 50670-901, Recife-PE, †Institute for Technological Research of \\ State of São Paulo/CTPP, 05508-901, São Paulo/SP, Brazil and †Rapsodee Research Center, E’cole des Mines d’Albi, 81013 Albi, France
}

Received 12 July 2010, Accepted 17 September 2010

Keywords: benzophenone-3, carnauba wax, dispersions, isodecyl oleate, nanostructured lipid carriers

\begin{abstract}
Synopsis
Nanostructured lipid carriers (NLCs) are potential active delivery systems based on mixtures of solid lipids and liquid oil. In this paper, aqueous dispersions of NLCs were prepared by a hot highpressure homogenization technique using carnauba wax as the solid lipid and isodecyl oleate as the liquid oil. The preparation and stability parameters of benzophenone-3-loaded NLCs have been investigated concerning particle size, zeta potential and loading capacity to encapsulate benzophenone-3, a molecular sunscreen. The current investigation illustrates the effect of the composition of the lipid mixture on the entrapment efficiency, in vitro release and stability of benzophenone-3-loaded in these NLCs. A loading capacity of approximately $5 \%$ of benzophenone-3 $\left(\mathrm{m}_{\mathrm{BZ}-3} / \mathrm{m}_{\text {lipids }}\right)$ was characteristic of these systems.
\end{abstract}

\section{Résumé}

Les particules lipidiques, nommées NLCs (nanostructured lipid carriers), sont de potentiels vecteurs actifs à base de mélanges de lipides solides et de lipides liquides. Dans le présent article, les dispersions aqueuses de NLCs ont été préparées par la technique chaude à haute pression d'homogénéisation à l'aide de la cire de carnauba comme lipide solide et de l'oléate d'isodécyle comme huile liquide. La taille des particules, le potentiel zêta et la capacité d'encapsuler la benzophénone-3, un filtre solaire moléculaire, ont été étudiés pour optimiser la préparation et déterminer les paramètres de stabilité de la benzophénone-3-NLCs. Le travail illustre l'effet de la composition du mélange lipidique sur l'efficacité d'encapsulation, la libération in vitro et la stabilité de la benzophénone-3-encapsulée dans ces NLCs.

\section{Introduction}

Lipid nanoparticles with solid particle matrix solid lipid nanoparticles (SLNs) are derived from o/w emulsions by simply replacing the liquid lipid (oil) with a solid lipid at body temperature. They were developed at the beginning of the nineties with the purpose of increasing physicochemical stability of both the incorporated active substances and the system itself [1]. They have been used as drugs and cosmetics delivery systems [2].

Correspondence: Maria Inês Ré. Rapsodee Research Center, E'cole des Mines d'Albi, 81013 Albi, France. Tel.: (33) 56349 3299; fax: (33) 56 349 3025; e-mail: maria-ines.re@enstimac.fr
Nanostrucutured lipid carriers (NLCs) constitute a second generation of this technology. They are produced using a blend of a solid lipid with a liquid lipid, this blend also being solid at body temperature [3]. The original purpose of these mixtures is to avoid lipid re-crystallization causing an expulsion of the enclosed active substances observed with SLNs. Since the last decade, NLCs have been studied intensively as suitable vehicles for the dermal delivery of different drugs and cosmetic actives [4-7].

Binary mixtures with different compositions have been proposed to develop NLCs. Among them are stearic acid with oleic acid [8], cetyl palmitate and miglyol ${ }^{\circledR} 812$ (caprylic/capric triglycerides) [9], and glyceryl tripalmitate and miglyol ${ }^{\circledR} 812$ (caprylic/capric triglycerides) [10]. Carnauba wax is described as a plastic solid obtained from the carnauba palm tree. It is a very hard material having a melting point range from 81 to $86^{\circ} \mathrm{C}$ and consists of a complex mixture of high molecular weight esters of acids and hydroxyacids [11]. Isodecyl oleate is a well-known emollient showing high fluidity and causing no irritation when it is spread onto human skin [12]. A binary mixture between carnauba wax as a thermoplastic lipid and decyl oleate as the liquid lipid was proposed by Villalobos-Hernández and Müller-Goymann and co-workers [13-15] to encapsulate inorganic sunscreens such as barium sulphate, strontium carbonate and titanium dioxide. More recently, a similar binary lipid matrix was used to encapsulate butyl methoxydibenzoylmethane and octyl methoxycinnamate as organic sunscreens, and also titanium dioxide [16]. The results reported show that the combination of the properties of both excipients constitutes a potential medium for the dermal application of these inorganic compounds.

NLCs, in a similar way to other disperse systems, may face stability problems attributed to physical, chemical and microbiological factors. Consequently, the destabilization of those systems can be reflected by changes in particle size, homogeneity or chemical composition [17]. Stability studies can be used to identify the weakness of a formulation. The information generated through the stability studies can be used for reformulation purposes because of the properties such as the type of emulsifier and its concentration, the zeta potential of the particles, the most thermodynamically stable particle size and the use of preservatives [18]. On the other hand, besides the stability of the system, the incorporation of the active substances into the lipid matrices, defined as loading capacity or entrapment efficiency, also has to be evaluated to judge the suitability of a nanoscale carrier system [19]. This parameter can be related to different variables, among them the active substance/lipid ratio [19]. 
In this work, isodecyl oleate was incorporated as the liquid oil into carnauba wax by a hot high-pressure homogenization technique. This study aims to obtain experimental evidence about the effect of the process and formulation parameters such as the active substance/lipid ratio on the physicochemical characteristics of these systems.

\section{Materials}

\section{Methods}

Carnauba wax (T-1) provided as a courtesy of Cerapeles Ltda (Caucaia, CE, Brazil) and Isodecyl oleate as a courtesy of Dhaymers (São Paulo, SP, Brazil) were used as lipid material. Polysorbate 80 (Tween 80) and Poloxamer 188 (Pluronic F68), a courtesy of BASF (São Paulo, SP, Brazil), were used as emulsifiers for the formulations. Dimeticone was purchased from Dow Corning (Hortolândia, SP, Brazil), and Phenoxiethanol F was used as a preservative in the formulations. The molecular sunscreen Benzophenone-3 (BZ-3) was purchased from Delaware (Porto Alegre, RS, Brazil).

\section{Preparation of lipidic nanoparticles (NLC) and their characteriza- tion}

\section{Preparation of blank NLCs}

The aqueous phase was prepared by dispersing the surfactant in water. The lipid phase consisting of a binary mixture of carnauba wax and isodecyl oleate was melted at $85 \pm 5^{\circ} \mathrm{C}$. The aqueous nanodispersions were prepared in two successive steps. First, the melted lipid phase was emulsified in the aqueous phase using high shear dispersion system, Ultraturrax ${ }^{\circledR}$ (Diax 900; Heidolph, Schawabach, Germany) at $26.000 \mathrm{rpm}$ for $4 \mathrm{~min}$ at $85 \pm 5^{\circ} \mathrm{C}$. Then, the pre-emulsion formed was homogenized using a highpressure homogenizer of Invensys APV, Model APV-2000 (Gaulin, Germany) at pressures between 400 and 900 bar, with between 2 and a maximum of eight homogenization cycles (passes). The formed nanoemulsion was finally cooled to form the solid nanodispersions.

Preparation of benzophenone-3-loaded NLCs dispersions The formulation was produced by dispersing the lipid phase containing the BZ-3 as expressed in Table I, into the aqueous phase

Table I The composition of NLCs containing BZ-3

\section{Composition (wt \%)}

\begin{tabular}{lll}
\cline { 2 - 3 } Ingredients & Blank NLCs & BZ-3-loaded NLCs \\
\hline Lipid phase & & \\
Carnauba wax & 5 & 5 \\
Isodecyl oleate & 5 & 5 \\
Benzophenone-3 & - & $0.5 ; 1.0$ and 5.0 \\
Dimeticone & 1 & 1 \\
Aqueous phase & & \\
Polysorbate 80 & 1 & 1 \\
Phenoxiethanol-F & 0.2 & 0.2 \\
Distilled water & q.s. 100 & q.s. 100 \\
\end{tabular}

wt, weight; q.s., quantum sufficient; BZ-3, benzophenone-3; NLCs, nanostructured lipid carriers. using high-pressure homogenization. The phases were initially predispersed and subsequently high-pressure homogenized at 900 bar within eight cycles (Homogenizer Invensys APV, Model APV2000). After the homogenization, the product was cooled down at room temperature.

Preparation of Nile red-loaded NLCs dispersions

The same procedure as for blank NLCs dispersion was also used to prepare Nile red NLCs dispersion containing 0.04 wt $\%$ of dye.

\section{Nanoparticles characterization}

Particle size and polydispersity index

All the measurements were performed in triplicates using a Particle Size Analyser (Malvern Zetamaster ${ }^{\circledR}$, Malvern Instruments Ltd., Worchestershire, UK) at a temperature of $25 \pm 2{ }^{\circ} \mathrm{C}$ and at $90^{\circ}$ of the incident beam applying the principle of photon correlation spectroscopy (PCS). Dispersions were diluted with distilled water (refractive index 1.33) to ensure that the light-scattering intensity was within the instrument's sensitivity range. The sensitivity range was 20 to $1000 \mathrm{~nm}$.

\section{Zeta potential}

The zeta potential was determined on a Zeta Potential Analyser (Malvern Zetamaster ${ }^{\circledR}$ ) and was measured by determining the electrophoretic mobility of the particles. It reflects the particle surface and indicates the physical stability of the nanodispersions. The measurements were performed in distilled water. Each sample was diluted appropriately, and the results were determined by the mean of fifteen measures.

\section{Encapsulation efficiency}

The amount of BZ-3 encapsulated per unit weight of nanoparticles was determined after the separation of the solid phase (free crystals and solid lipids) from the aqueous medium. A known dilution of the NLCs dispersion was prepared and centrifuged at $10.400 \mathrm{~g}$ (Selecta Medfriger-BL Centrifuge) for $60 \mathrm{~min}$. The precipitated was washed, first with saccharose $(20 \mathrm{wt} \%)$ and then with $0.2 \mathrm{wt} \%$ SLS solution. It was dried in a vacuum desiccator for $8 \mathrm{~h}$. After appropriate dilution, the BZ-3 content was determined by HPLC analysis. The method described by Sarveiya [20] and Paese [21] was used for the analysis. The HPLC system consisted of a Shimadzu Prominence Chromatograph equipped with a UV-vis detector, column LiChrospher $100 \mathrm{RP}-18(5 \mu \mathrm{m}, 250 \times 4 \mathrm{~mm}$ and a guardcolumn $5 \mu \mathrm{m}$ ). The mobile phase (methanol: water in the ratio of $95: 5)$ was run at a flow rate of $1.0 \mathrm{~mL} \mathrm{~min}^{-1}$, and the ultraviolet absorption was read at $289 \mathrm{~nm}$.

\section{Stability studies}

The stability of the nanosuspensions was evaluated using a Turbiscan ${ }^{\circledR}$ Lab (Formulaction, France). The nanosuspensions were sampled immediately after preparation, and the sample was transferred to a glass cylindrical cell and analysed by a light beam emitted in near infrared $(880 \mathrm{~nm})$ wavelength which scanned the sample cell. Two synchronous optical sensors received light transmitted through the sample and light backscattered by the sample, respectively. The backscattering (BS) was directly dependent on the particle mean diameter. The sample in the cell was scanned every $30 \mathrm{~min}$ for $24 \mathrm{~h}$ at $25^{\circ} \mathrm{C}$, and the change in BS in unit time was taken as a measure of the stability of the nanosuspensions. The physical stability of NLCs was also determined by measuring the particle size of the formulations at 0,15 and 30 days. 
Differential scanning calorimetry (DSC)

DSC was performed using a heat flux instrument (DSC 851 tler Toledo International Inc., Zurich, Switzerland) to characterize the thermal behaviour of the lipid nanocarriers. A nitrogen purge at a flow rate of $80 \mathrm{~mL} \mathrm{~min}{ }^{-1}$ was used to provide an inert gas atmosphere in the DSC cell. The system was calibrated using an indium standard, and the sample was run against a hermetic empty reference pan. In all cases, a heating rate of $10^{\circ} \mathrm{C} \mathrm{min}^{-1}$ was used.

\section{In vitro experiments}

Occlusive effect

To evaluate the occlusive properties of the wax-oil NLCs, an in vitro occlusion test described by Vringer was performed [22]. Glass bottles $(35 \mathrm{~mL})$ were filled with $30 \mathrm{~g}$ of water and covered with a filter paper (cellulose filters, $125 \mathrm{~mm}$, Whatman number 4, U.S.A.). Three hundred microlitres of sample was spread homogeneously on the filter surface $\left(3.36 \mathrm{~cm}^{2}\right)$, and the sample was subsequently stored at $32^{\circ} \mathrm{C}$ for $48 \mathrm{~h}$ to mimic the temperature of the skin surface. The weight of water remaining in the glass bottles was weighed after 8 , 24 and $48 \mathrm{~h}$. The glass bottles covered with the filter paper, which was spread with water, was used as a reference. All experiments were performed in four replicates $(n=4)$. The occlusion factor $(F)$ was computed by the following equation (1):

$$
F=\frac{A-B}{A} \times 100
$$

$A$ stands for the water loss without the sample (reference) and $B$ is the water loss with the sample. An $F$ value of 0 means no occlusive effect compared to the reference, whereas an $F$ value of 100 means maximum occlusiveness.

\section{Skin penetration test}

The skin penetration test was performed using fresh ears of domestic pigs obtained from a local slaughterhouse on the day of the experiment. Full thickness porcine ear dorsal skins were excised and immediately mounted in a Franz diffusion cell (Microette-Hanson $\left.{ }^{\circledR}\right)$ with the dermal side facing downwards into the receptor compartment, which was filled with the acceptor medium of the compartment, with $4 \mathrm{~mL}$ of isotonic phosphate buffer $(\mathrm{pH} 7.4$ ) containing $5 \% \mathrm{w} / \mathrm{w}$ of polysorbate 80 . The donor compartment was then filled with $5 \mathrm{~mL}$ of the formulations: Nile red-loaded NLCs dispersion and Nile red solubilized in isodecyl oleate were applied. The total available diffusion area of the cell was $2.3 \mathrm{~cm}^{2}$. The system was maintained at $37^{\circ} \mathrm{C}$ and the receptor medium stirred at $300 \mathrm{rpm}$ for up to $8 \mathrm{~h}$. The treated skins were then removed from the Franz diffusion cells, frozen in liquid nitrogen by immersion in Tissue-Tek ${ }^{\circledR}$ O.C.T. ${ }^{\mathrm{TM}}$ (Matrix for cryostat) and sectioned using a cryostate into slices of about $15 \mu \mathrm{m}$, from stratum corneum towards the dermis. The skin slices were investigated under fluorescence microscopes using confocal laser scanning microscopy (CLSM, Model: LSM 510 Meta Microscope, Carl Zeiss, Jena, Germany). The images obtained with this technique were overlaid to obtain the information of the Nile red distribution in the different skin layers.

\section{In vitro release}

The in vitro release was performed using a synthetic membrane of cellulose acetate. It was mounted in a Franz diffusion cell (Micro-
ette-Hanson ${ }^{\circledR}$, Chatsworth, CA, USA), and the acceptor compartment was filled with $4 \mathrm{~mL}$ of isotonic phosphate buffer ( $\mathrm{pH} 7.4$ ) containing $5 \% \mathrm{w} / \mathrm{w}$ of polysorbate 80 . The donor compartment was then filled with $5 \mathrm{~mL}$ of the formulations containing benzophenone-3 $(0.5 \% \mathrm{w} / \mathrm{w})$. The total available diffusion area of the cell was $2.3 \mathrm{~cm}^{2}$. The system was maintained at $37^{\circ} \mathrm{C}$ and the receptor medium stirred at $300 \mathrm{rpm}$. At regular intervals - 1, 2, 3, 4 and $8 \mathrm{~h}, 1 \mathrm{~mL}$ of the receptor phase was removed for the determination of the total drug content by HPLC assay (as described before) and replaced by an equal volume of fresh receptor solution.

\section{Results}

\section{Preparation of blank NLCs and their characterization}

\section{Experimental design}

One aim of this study was to optimize the carnauba wax-based nanocarriers regarding the particle size and polydispersity. These characteristics are influenced by process parameters such as the concentrations of surfactant and total lipids, the ratio of wax: oil and the homogenization conditions (pressure and cycles number).

To investigate these effects, the experiments started following two 4-factorial 2-level type experimental designs and statistical analysis applied successively to limit the number of parameters influencing the preparation process.

First, the four independent factors at two levels were taken into consideration without repetition, resulting in 16 scheduled experiments. The homogenization conditions were kept constant (600 bar, 5 homogenization cycles) and nanodispersions of carnauba wax-isodecyl oleate were obtained under different formulation conditions. Nanosuspensions were prepared containing 5 or $20 \mathrm{wt} \%$ of a binary mixture of carnauba wax and isodecyl oleate, the ratio of wax: oil being fixed at $2: 1$ or $1: 1$, based on the previous data reported in the literature [23]. The aqueous phase consisted of an aqueous solution containing polysorbate 80 or poloxamer 188 , as an alternative surfactant. Two different surfactant concentrations were fixed, namely 1 and $3 \mathrm{wt} \%$.

The formulation conditions were fixed (ratio of wax: oil $1: 1$; aqueous phase containing $1 \mathrm{wt} \%$ polysorbate 80 ) and the homogenization conditions were varied (homogenization cycle: 2 and 8; homogenization pressure: 400 and 900 bar; pre-emulsification time: 4 and $8 \mathrm{~min}$; cooling rate after homogenization: ice bath and cooling down at room temperature), resulting in 16 more scheduled experiments.

For the analysis of physical stability of NLCs, the product was investigated with PCS analysis. PCS yields the mean particle size and the polydispersity index (PI) as a measure of the width of the distribution.

Table II shows that the particle size average ranged from a nanometric size $(277 \mathrm{~nm})$ to some micrometres $(7.7 \mu \mathrm{m})$ depending on the formulation composition. Narrow dispersions comprise PI values between 0.1 and 0.25 , and broad dispersions are reflected by PI values $>0.25$ [24]. Hence, according to Table II, all dispersions can be labelled as broad disperse.

Results were analysed using the software sTatistica for WINDOWS 5.00 (StatSoft, Inc.). From a Pareto diagram (data not shown) and response surface methodology, it could be seen that the wax: oil ratio and the surfactant were the factors more statistically significant affecting the particle average size and the PI $(P<0.05)$. The surface graphics are three-dimensional and show a better visualization of the effect of these factors on the particle size average and PI (Fig. 1). 
Table II Particle size average (PSA) and polydispersity index (PI) of the nanosuspensions for different formulation compositions

\begin{tabular}{|c|c|c|c|c|c|c|c|c|}
\hline \multirow[b]{2}{*}{ Test } & \multirow[b]{2}{*}{$\begin{array}{l}\text { Surfactant } \\
\text { concentration } \\
\text { (wt\%) }\end{array}$} & \multirow[b]{2}{*}{$\begin{array}{l}\text { Lipids } \\
\text { total } \\
\text { (\%wt) }\end{array}$} & \multirow[b]{2}{*}{$\begin{array}{l}\text { Type of } \\
\text { surfactant }\end{array}$} & \multirow[b]{2}{*}{$\begin{array}{l}\text { Proportion } \\
\text { Wax : Oil }\end{array}$} & \multicolumn{4}{|c|}{ PSA $(n m)$ and PI } \\
\hline & & & & & $\begin{array}{l}\text { PSA } \\
t_{0}\end{array}$ & PI & $\begin{array}{l}\text { PSA } \\
t_{10}\end{array}$ & PI \\
\hline 1 & 3 & 20 & Polysorbate 80 & $1: 1$ & 277.4 & 0.41 & 286.7 & 0.72 \\
\hline 2 & 1 & 20 & Polysorbate 80 & $1: 1$ & 405.0 & 0.31 & 370.9 & 0.13 \\
\hline 3 & 3 & 5 & Polysorbate 80 & $1: 1$ & 570.5 & 0.33 & 595.3 & 0.47 \\
\hline 4 & 1 & 5 & Polysorbate 80 & $1: 1$ & 482.5 & 0.41 & 542.7 & 1.00 \\
\hline 5 & 3 & 20 & Poloxamer 188 & $1: 1$ & 1612.5 & 1.00 & 512.3 & 0.50 \\
\hline 6 & 1 & 20 & Poloxamer 188 & $1: 1$ & 3663.9 & 0.63 & 5626.1 & 0.77 \\
\hline 7 & 3 & 5 & Poloxamer 188 & $1: 1$ & 567.0 & 0.35 & 559.5 & 0.83 \\
\hline 8 & 1 & 5 & Poloxamer 188 & $1: 1$ & 223.3 & 0.24 & 223.6 & 0.20 \\
\hline 9 & 3 & 20 & Polysorbate 80 & $2: 1$ & 322.7 & 0.31 & 307.5 & 0.24 \\
\hline 10 & 1 & 20 & Polysorbate 80 & $2: 1$ & 1471.9 & 1.00 & 6304.8 & 1.00 \\
\hline 11 & 3 & 5 & Polysorbate 80 & $2: 1$ & 1008.9 & 0.77 & 763.8 & 1.00 \\
\hline 12 & 1 & 5 & Polysorbate 80 & $2: 1$ & 741.5 & 1.00 & 2627.3 & 1.00 \\
\hline 13 & 3 & 20 & Poloxamer 188 & $2: 1$ & 1912.9 & 1.00 & 3823.3 & 0.96 \\
\hline 14 & 1 & 20 & Poloxamer 188 & $2: 1$ & 7736.0 & 0.98 & 4077.0 & 0.89 \\
\hline 15 & 3 & 5 & Poloxamer 188 & $2: 1$ & 2657.8 & 1.00 & 2109.3 & 1.00 \\
\hline 16 & 1 & 5 & Poloxamer 188 & $2: 1$ & 5613.5 & 1.00 & 4102.9 & 1.00 \\
\hline
\end{tabular}

$t_{0}=$ immediately after homogenization; $t_{10}=10$ days after preparation.

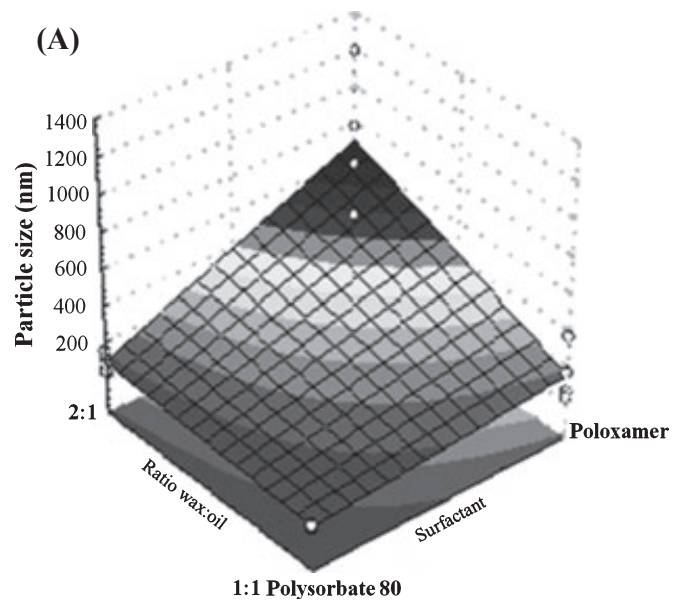

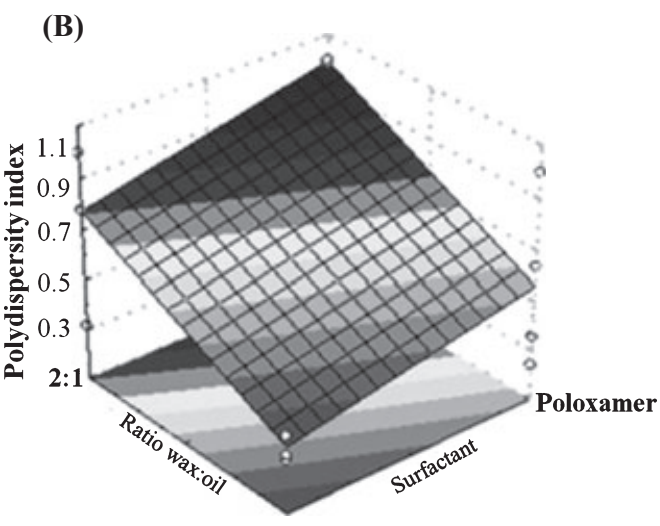

1:1 Polysorbate 80

Figure 1 Response surface methodology (effect of wax: oil ratio, type and concentration of the emulsifier on the particle size average (A) and polydispersity index (B) of the lipid nanoparticles.

Table III shows that the particle size ranged from 235 to $4509 \mathrm{~nm}$, depending on the homogenization conditions. Smaller particles $(<265 \mathrm{~nm})$ and narrow dispersions comprising of PI values between 0.12 and 0.18 were favoured by the highest homogenization pressure (e.g., T17, T18, T25, T29, T30). They also showed only minor changes when stored for 10 days. The visualization of these homogenization conditions effects is given in Fig. 2.

To summarize, homogenization conditions were optimized to produce carnauba wax-oil NLCs with good physical stability. Most efficient homogenization was achieved at a pressure of 900 bar and 8 cycles for polysorbate 80 stabilized nanoparticles and at a wax: oil ratio of $1: 1$. Blank NLCs obtained with these conditions were submitted to additional in vitro analyses (occlusive properties and skin penetration of a fluorescent dye from NLCs).

\section{Occlusive properties}

The formation of a protective and occlusive film of SLN and NLCs on the skin has been described in the literature [25]. The occlusivity of the aqueous blank NLCs dispersion was evaluated quantitatively in vitro by a filter test. The occlusion factor was determined as a function of time, i.e., after 8,24 and $48 \mathrm{~h}$ of storage at $32^{\circ} \mathrm{C}$. 
Table III Particle size average (PSA) and polydispersity index (PI) of the nanosuspensions for different homogenization conditions

\begin{tabular}{|c|c|c|c|c|c|c|c|c|}
\hline \multirow[b]{3}{*}{ Test } & \multirow[b]{3}{*}{$\begin{array}{l}\text { Homogenization } \\
\text { cycles }\end{array}$} & \multirow[b]{3}{*}{$\begin{array}{l}\text { Homogenization } \\
\text { pressure (bar) }\end{array}$} & \multirow[b]{3}{*}{$\begin{array}{l}\text { Cooling } \\
\text { method }\end{array}$} & \multirow[b]{3}{*}{$\begin{array}{l}\text { Pre-emulsion } \\
\text { time (min) }\end{array}$} & \multicolumn{4}{|c|}{ PSA $(n m)$ and PI } \\
\hline & & & & & PSA & PI & PSA & PI \\
\hline & & & & & $t_{0}$ & & $t_{10}$ & \\
\hline 17 & 8 & 900 & $\mathrm{RT}$ & 8 & 235.2 & 0.18 & 257.0 & 0.17 \\
\hline 18 & 2 & 900 & $\mathrm{RT}$ & 8 & 262.4 & 0.13 & 249.2 & 0.19 \\
\hline 19 & 8 & 400 & $\mathrm{RT}$ & 8 & 4509.1 & 1.00 & 386.4 & 1.00 \\
\hline 20 & 2 & 400 & $\mathrm{RT}$ & 8 & 1736.6 & 1.00 & 1358.4 & 1.00 \\
\hline 21 & 8 & 900 & Ice batch & 8 & 292.2 & 0.57 & 295.0 & 0.51 \\
\hline 22 & 2 & 900 & Ice batch & 8 & 437.5 & 1.00 & 862.5 & 0.68 \\
\hline 23 & 8 & 400 & Ice batch & 8 & 441.2 & 1.00 & 419.1 & 1.00 \\
\hline 24 & 2 & 400 & Ice batch & 8 & 1589.7 & 1.00 & 958.5 & 1.00 \\
\hline 25 & 8 & 900 & $\mathrm{RT}$ & 4 & 263.1 & 0.33 & 261.5 & 0.18 \\
\hline 26 & 2 & 900 & $\mathrm{RT}$ & 4 & 259.8 & 0.31 & 347.5 & 1.00 \\
\hline 27 & 8 & 400 & $\mathrm{RT}$ & 4 & 696.0 & 1.00 & 335.3 & 1.00 \\
\hline 28 & 2 & 400 & $\mathrm{RT}$ & 4 & 287.5 & 0.60 & 324.8 & 0.55 \\
\hline 29 & 8 & 900 & Ice batch & 4 & 251.3 & 0.12 & 257.6 & 0.15 \\
\hline 30 & 2 & 900 & Ice batch & 4 & 265.2 & 0.16 & 261.9 & 0.11 \\
\hline 31 & 8 & 400 & Ice batch & 4 & 2735.6 & 1.00 & 6589.0 & 1.00 \\
\hline 32 & 2 & 400 & Ice batch & 4 & 5231.9 & 1.00 & 1567.0 & 1.00 \\
\hline
\end{tabular}

$t_{0}=$ immediately after homogenization; $t_{10}=10$ days after preparation.

$\mathrm{RT}=$ room temperature.
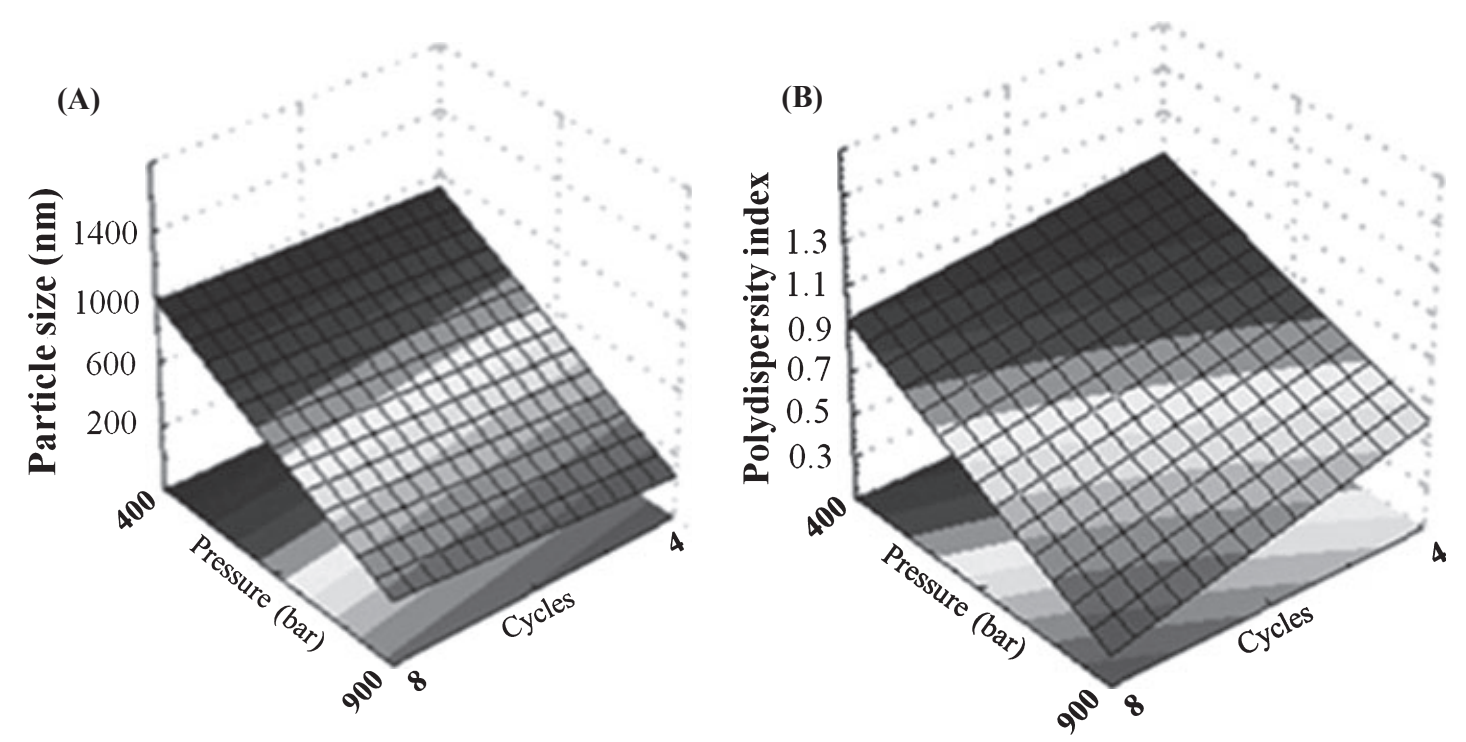

Figure 2 Response surface methodology (effect of homogenization pressure and number of cycles on the particle size average (A) and polydispersity index (B) of the lipid nanoparticles).

Figure 3 shows that the blank NLCs has occlusive properties (55-60\%) probably because of its nanometric size. Occlusion factors of the same magnitude were previously observed for lipid nanoparticles of approximately $200 \mathrm{~nm}[26,27]$. Although studies of this kind do not fully mimic the natural conditions of moisture loss, it is observed that the lower the size of the particles, the greater the barrier for evaporation.
Penetration of fluorescence dye on the skin from NLCs

In addition, the skin penetration of Nile red-loaded NLCs dispersion composed of carnauba wax and isodecyl oleate was evaluated by CLSM. CLSM has been widely used to access the distribution within the skin of fluorescence dyes entrapped into nanoparticles $[28,29]$. 


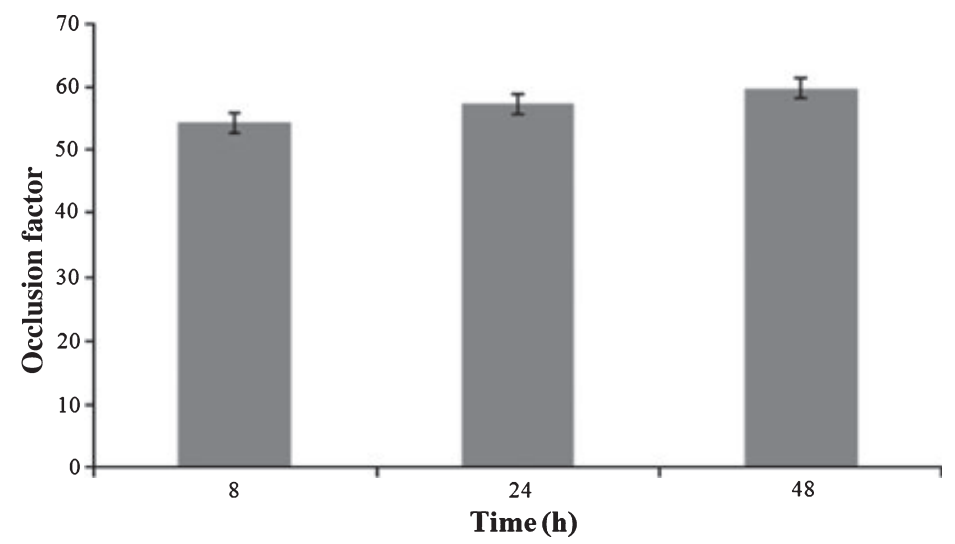

Figure 3 Occlusion factor of nanostructured lipid carriers dispersions at various times after application. Data give occlusion factor mean values \pm standard deviations (SD) $(n=4)$ and error bars mean SD.
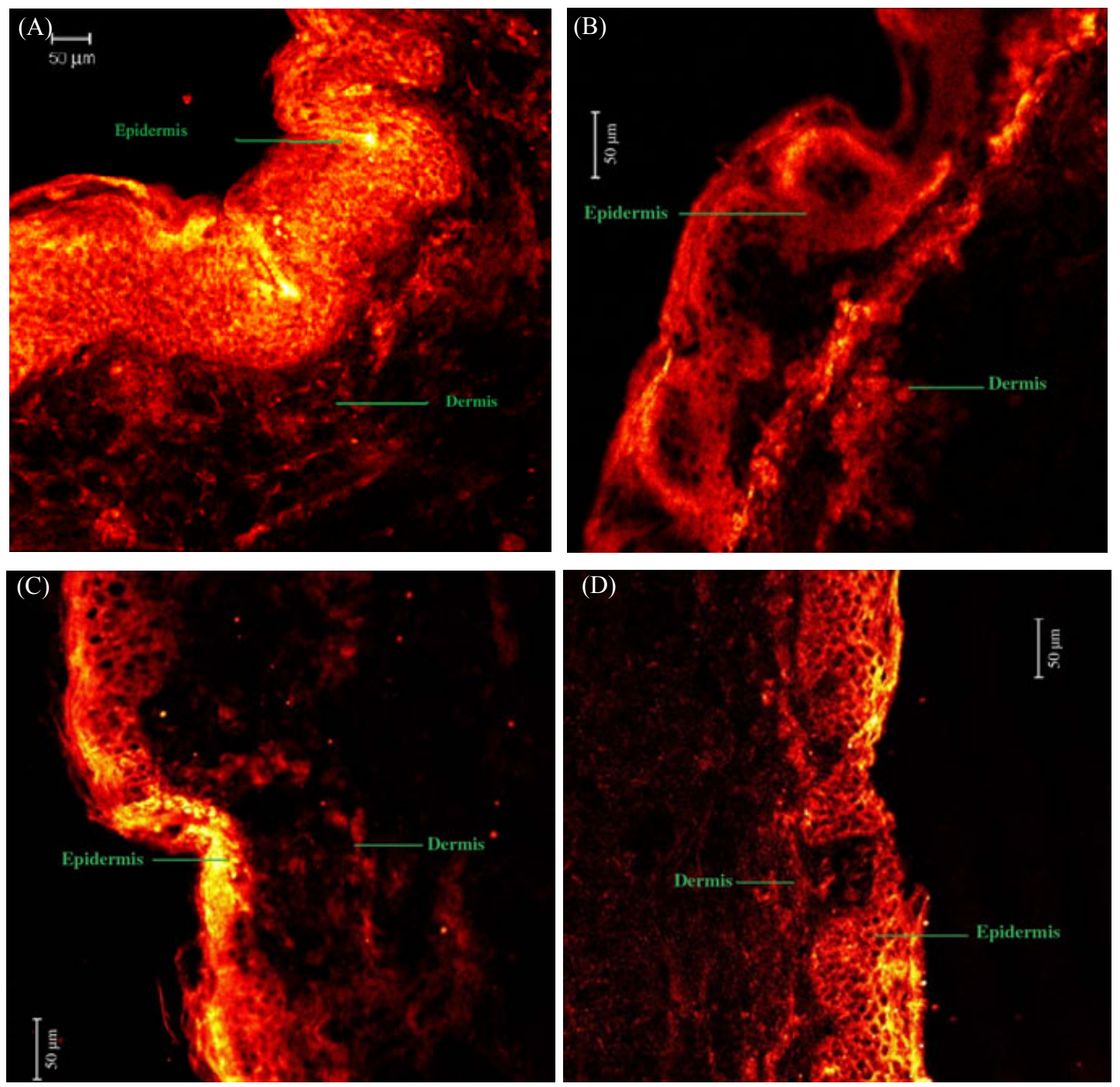

Figure 4 Penetration of Nile red into pig skin after 8 h. Nile red-loaded nanostructured lipid carriers dispersion (A, C); Nile red dispersed in isodecyl oleate (B, D). 
Table IV Differential scanning calorimetry data of the raw material and nanostructured lipid carriers dispersions

\begin{tabular}{lrlll}
\hline Sample & $\boldsymbol{\Delta} \mathbf{H}\left(\mathbf{J g}^{-\mathbf{1}}\right)$ & Onset $\left({ }^{\circ} \mathbf{C}\right)$ & $\mathbf{T}_{\mathbf{f}}\left({ }^{\circ} \mathbf{C}\right)$ & Endset $\left({ }^{\circ} \mathbf{C}\right)$ \\
\hline Benzophenone-3 & 90.08 & 62.73 & 64.35 & 67.85 \\
Carnauba wax & 163.15 & 79.89 & 83.96 & 86.06 \\
Carnauba wax: isodecyl & 69.24 & 66.89 & 78.62 & 82.57 \\
$\quad$ oleate (1: 1) & & & & \\
Blank NLCs & 64.19 & 76.73 & 80.25 & 83.29 \\
$\begin{array}{l}\text { BZ-3 loaded NLCs } \\
\quad\left(91 \mu \text { gBZ3 } \text { mg }^{-1} \text { lipids) }\right.\end{array}$ & 65.82 & 77.64 & 79.59 & 82.41 \\
\hline
\end{tabular}

NLCs, nanostructured lipid carriers.

Figure 4 depicts the fluorescence images of the vertical sections of pigskin after being treated with Nile red-loaded NLCs for $8 \mathrm{~h}$ (Fig. 4A,C) and Nile red dispersed in isodecyl oleate (Fig. 4B,D). It was clearly shown that dye penetration depends on the Nile red carrier used (NLCs or oil). NLCs showed the highest intensity of fluorescence compared to the dye-loaded oil. After $8 \mathrm{~h}$, the fluorescence distribution of NLCs was more pronounced in the SC. These images reveal that the presence of nanostructured lipidic carriers avoids the permeation of large amount of dye up to the dermis. This is different from what is observed when the dye is dispersed in oil, without carrier, where the dye is distributed in all layers of the skin.

\section{Preparation of benzophenone-3-loaded NLCs dispersions}

We report the characterization of BZ-3-loaded NLCs dispersion prepared by high-pressure homogenization at pressure of 900 bar and 8 cycles, with polysorbate 80 . To manufacture this, five BZ-3 concentrations $\left(0,48 ; 91 ; 231\right.$ and $\left.333 \mu \mathrm{g}_{\mathrm{BZ}-3} / \mathrm{mg}_{\text {lipids }}\right)$ were incorporated in the formulations.

\section{DSC analysis}

The study included an evaluation of the raw materials and mixtures thereof using DSC to appreciate possible changes in the crys- talline structure of the mixture wax-oil after the incorporation of BZ-3. Lipids of less ordered crystal lattices such as the mixture of carnauba wax and isodecyl oleate can favour the active substance inclusion and be more stable. Table IV and Fig. 5 show the DSC data of blank and BZ-3-loaded NLCs. BZ-3, carnauba wax and a physical mixture of carnauba wax and isodecyl oleate were also characterized for comparison.

Bulk wax showed a sharp endothermic event, ascribing to melting around $83.9^{\circ} \mathrm{C}$ (minimum) with and extrapolated onset of the melting peak at $79.9^{\circ} \mathrm{C}$. As shown in Fig. 5, the addition of oil (isodecyl oleate) into the matrix provoked a sharp decline in enthalpy in the bulk material from 163.1 to $69.2 \mathrm{~J} \mathrm{~g}^{-1}$ (Table IV). Also, an additional shift of the melting point to lower temperatures, with the difference between the onset and the minimum of the peak of about $13^{\circ} \mathrm{C}$, was observed. For less ordered crystals or amorphous solids, the melting of the substances requires much less energy than crystalline substances which need to overcome lattice forces. As a result, the lower melting enthalpy values observed for the binary mixture of wax-oil and also for blank NLCs suggest lower ordered lattice arrangement compared to the bulk materials. The loading of BZ-3 within these nanostructures did not provoke any considerable effect in the lipid matrix thermal behaviour under these experimental conditions.

\section{Encapsulation efficiency}

Table V shows the characteristics of the BZ-3-loaded NLCs, such as, the viscosity and $\mathrm{pH}$, particle size and polidispersity, zeta potential, entrapment efficiency and loading capacity.

To judge the suitability of a nanoscale carrier system, the incorporation of the active substances into the lipid matrices, defined as loading capacity, has to be evaluated in addition to the stability of the system. This parameter can be related to different variables, among them the active substance/lipid ratio. As shown in Table V, the entrapment efficiency of BZ-3 by the NLCs decreased from $91 \%$ to $17 \%$, depending on its initial content in the formulation. In fact, the results show the same loading capacity within the lipidic nanoparticles of $4-5 \mu \mathrm{g}_{\mathrm{BZ}-3} / \mathrm{mg}_{\text {lipids }}$ despite higher amounts in the initial formulation.
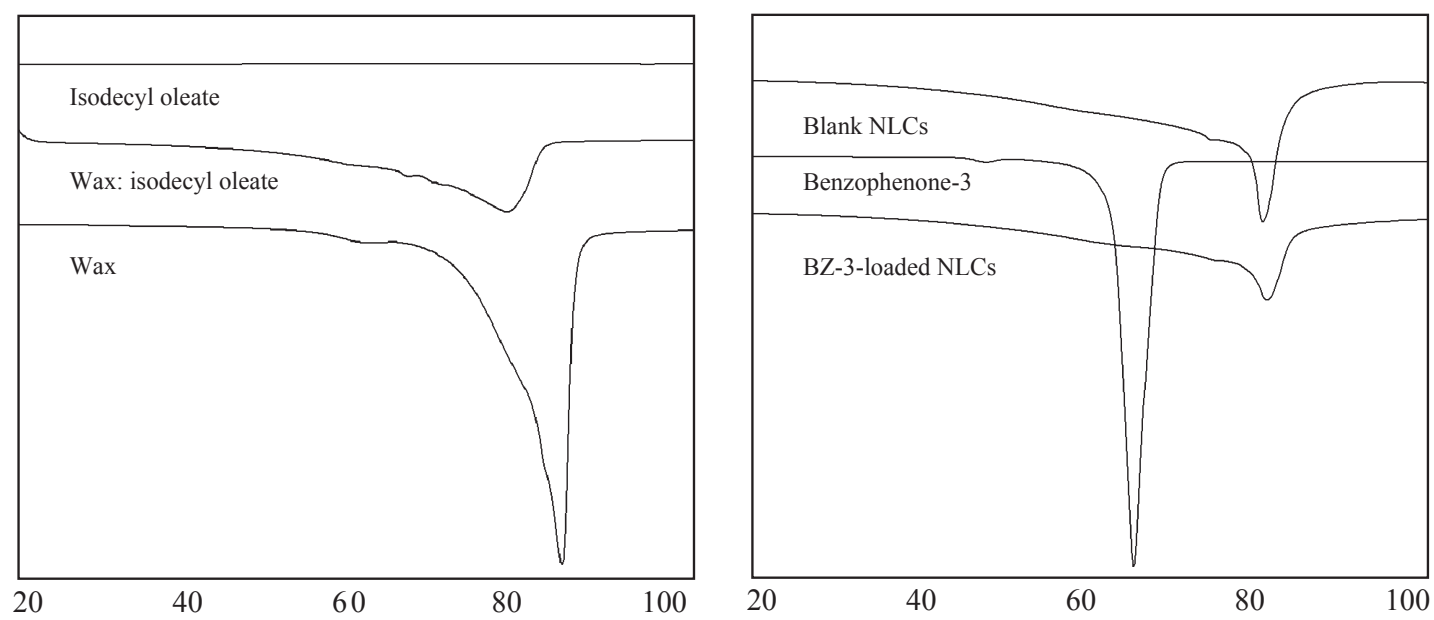

Figure 5 Differential scanning calorimetry data of the raw lipid material (carnauba wax, isodecyl oleate and its mixture), crystalline benzophenone-3 as well as blank and BZ-3-loaded nanostructured lipid carriers (NLCs). Exothermic up. 
Table V Characteristics of the BZ-3-loaded NLCs

\begin{tabular}{|c|c|c|c|c|c|c|c|c|}
\hline 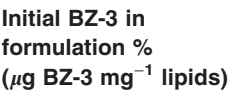 & $\begin{array}{l}\text { Time } \\
\text { (days) }\end{array}$ & $\begin{array}{l}\text { Diameter } \\
(\mathrm{nm})\end{array}$ & $\begin{array}{l}\text { Polydispersity } \\
\text { index }\end{array}$ & $\begin{array}{l}\text { Zeta } \\
\text { potential } \\
(\mathrm{mv})\end{array}$ & $\begin{array}{l}\text { Viscosity } \\
\text { (cps) }\end{array}$ & $\mathrm{pH}$ & $\begin{array}{l}\text { Entrapment } \\
\text { efficiency (\%) }\end{array}$ & $\begin{array}{l}\text { Loading capacity, } \\
\%\left(\mu \mathrm{g}_{\mathrm{Bz} 3} / \mathrm{mg}_{\text {lipids }}\right)\end{array}$ \\
\hline \multirow[t]{3}{*}{ Blank } & $t_{0}$ & $266.4 \pm 0.70$ & $0.139 \pm 0.019$ & $-32.4 \pm 1.6$ & 1.95 & 5.31 & * & * \\
\hline & $t_{15}$ & $274.8 \pm 1.40$ & $0.100 \pm 0.046$ & $-28.8 \pm 2.2$ & 2.00 & 5.77 & * & * \\
\hline & $t_{30}$ & $205.3 \pm 2.38$ & $0.186 \pm 0.023$ & $-27.2 \pm 2.8$ & 2.04 & 5.42 & * & * \\
\hline \multirow[t]{3}{*}{4.8} & $t_{0}$ & $266.3 \pm 0.90$ & $0.074 \pm 0.029$ & $-35.1 \pm 0.7$ & 2.02 & 5.47 & 91.0 & 3.60 \\
\hline & $t_{15}$ & $278.4 \pm 6.00$ & $0.100 \pm 0.006$ & $-38.5 \pm 1.9$ & 1.90 & 5.32 & 87.6 & 3.40 \\
\hline & $t_{30}$ & $210.0 \pm 1.20$ & $0.103 \pm 0.030$ & $-34.1 \pm 2.0$ & 2.12 & 5.73 & 58.8 & 2.20 \\
\hline \multirow[t]{3}{*}{9.1} & $t_{0}$ & $278.5 \pm 0.10$ & $0.104 \pm 0.014$ & $-34.0 \pm 3.3$ & 3.69 & 5.04 & 63.7 & 4.70 \\
\hline & $t_{15}$ & $291.1 \pm 4.80$ & $0.091 \pm 0.032$ & $-34.7 \pm 12.1$ & 3.05 & 5.01 & 57.9 & 4.40 \\
\hline & $t_{30}$ & $259.3 \pm 8.90$ & $0.015 \pm 0.008$ & $-39.2 \pm 10.0$ & 2.02 & 4.67 & 55.2 & 4.30 \\
\hline \multirow[t]{3}{*}{23.1} & $t_{0}$ & $314.4 \pm 6.00$ & $0.052 \pm 0.031$ & $-33.1 \pm 0.7$ & 2.15 & 5.23 & 25.5 & 5.20 \\
\hline & $t_{15}$ & $317.6 \pm 9.30$ & $0.041 \pm 0.018$ & $-36.8 \pm 1.2$ & 1.98 & 5.12 & 24.7 & 4.80 \\
\hline & $t_{30}$ & $302.1 \pm 5.80$ & $0.153 \pm 0.126$ & $-32.8 \pm 1.0$ & 2.20 & 4.91 & 20.3 & 4.00 \\
\hline \multirow[t]{3}{*}{33.3} & $t_{0}$ & * & * & * & 2.00 & 5.38 & 17.1 & 5.10 \\
\hline & $t_{15}$ & $302.1 \pm 24.40$ & $0.184 \pm 0.058$ & $-38.5 \pm 0.5$ & 1.22 & 5.51 & 14.9 & 4.40 \\
\hline & $t_{30}$ & $359.1 \pm 8.20$ & $0.215 \pm 0.187$ & $-33.9 \pm 0.7$ & 2.45 & 5.61 & 12.4 & 3.50 \\
\hline
\end{tabular}

*The measurements were not determined.

NLCs were prepared using polysorbate 80 at a final concentration of $1 \%(w / w)$ as emulsifier and at homogenization conditions of 900 bar and 8 cycles.

\section{Stability studies}

The physical stability of NLCs dispersions is a complex issue and can be influenced by a number of factors including particle size, viscosity and environmental conditions such as temperature.

The stability of the NLCs dispersions was first monitored by the BS profiles produced by Turbiscan ${ }^{\circledR}$ Lab (Formulaction, Toulouse, France) immediately after production. The biggest advantage of this technique is that it can detect changes in the particle size of nanodispersion long before they become visible.

The Turbiscan ${ }^{\circledR}$ Lab measured the light backscattered by the sample, which is directly dependent on the particle mean diameter at preset intervals (30 min in this work) over a predetermined period of time ( $24 \mathrm{~h}$ in this study). Figure 6 shows the BS profiles of the BZ-3loaded NLCs. No variations in these profiles are observed over $24 \mathrm{~h}$ within formulations containing 48 to $231 \mu \mathrm{g}_{\mathrm{BZ}-3} / \mathrm{mg}_{\text {lipids }}$, suggesting that in this mass domain, particles are not interacting through colloidal forces. However, at the highest concentration of $333 \mu \mathrm{g}_{\mathrm{BZ}-3} /$ $\mathrm{mg}_{\text {lipids }}$, particles seem sufficiently close to each other for colloidal interactions to take place. Some agglomeration of the non-entrapped crystals of BZ-3 is probably taking place, causing enhanced kinetics of sedimentation in the lower part of the tube as measured by the change of the backscattered light.

The physical stability of NLCs was investigated with PCS analysis over a period of 30 days. PCS yields the mean particle size and the PI as a measure of the width of the distribution. Zeta potential and viscosity measurements of the samples stored at room temperature $\left(25^{\circ} \mathrm{C}\right)$ were also performed over the same period (Table V). After production under the same conditions, the blank NLCs dispersions show a narrow particle size distribution, which is completely in the nanometre range. Incorporation of BZ-3 $(0,4.8 ; 9.1 ; 23.1$ and $33.3 \%)$ slightly influenced the particle size. PCS data reveal a mean diameter of about 200-300 nm, which remains constant over a period of 30 days.

These observations coincided with the information derived from the zeta potential measurements. Table $\mathrm{V}$ also reveals that the zeta potential data values of BZ-3-loaded NLCs remained practically unchanged during this storage time. All the formulations exhibited negative values. The measurement of the zeta potential allows predictions about the stability of colloidal aqueous dispersions [30].
Figure 6 Effects of initial BZ-3 load on the stability of BZ-3loaded nanostructured lipid carriers dispersions prepared with polysorbate 80 at 900 bar and 8 cycles.

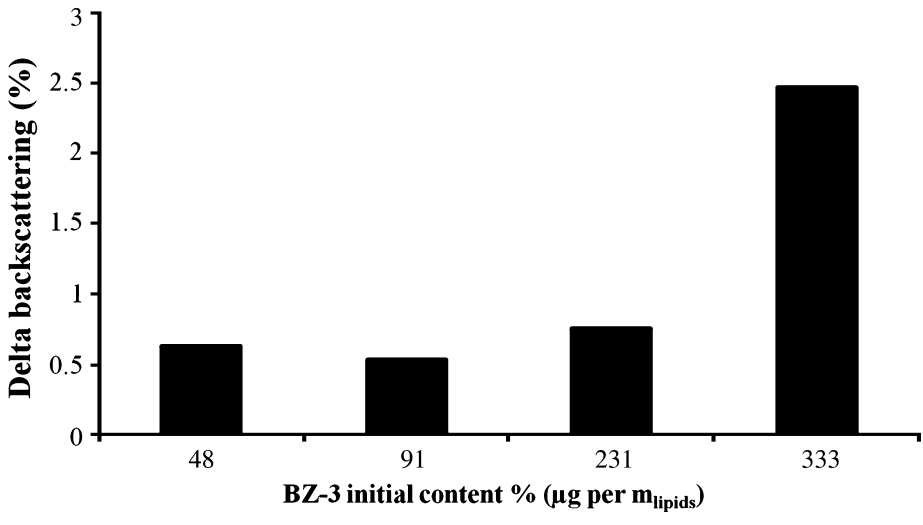




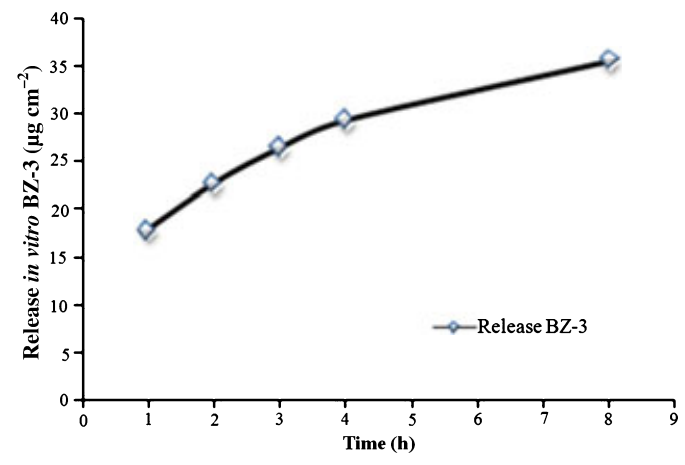

Figure 7 Kinetic release in vitro of BZ-3-loaded nanostructured lipid carriers of carnauba wax and isodecyl oleate.

Usually, particle aggregation is less likely to occur for charged particles with high zeta potential $(>-30 \mathrm{mV})$ because of electrical repulsion [31].

NLCs dispersions possess low viscosity (approximately $2 \mathrm{mPa} \mathrm{s}$ ) also unchanged during the storage time. From these results, it can be stated that BZ-3-loaded NLCs are physically stable under these shelf-life test conditions. Application of the pure aqueous NLCs dispersions to the skin is possible although semisolid preparations are normally preferred because of their more convenient application.

\section{In vitro release}

The in vitro permeation release ability of these nanocarriers was performed using Franz diffusion cells through a cellulose acetate membrane and a phosphate buffer saline as receptor fluid. The permeation study performed for $8 \mathrm{~h}$ indicates that the amount of BZ-3 in the receptor medium was increased with time, following a zeroorder kinetics with a steady permeation rate of $2.4 \mu \mathrm{g} \mathrm{cm}^{-2} \mathrm{~h}^{-1}$ (Fig. 7).

Several reasons could explain the small quantities of BZ-3 found in receptor medium after the application time such as the high lipophilicity of the active substance, associated with a high hydrophobicity of the lipid matrix, preventing diffusion from the NLCs into the receptor medium, or the use of a separation membrane in contact with the receptor medium which could influence the diffusion rate of BZ-3. On the other hand, the slow diffusion rate of BZ3 from the nanocarriers can indicate that the active substance was entirely encapsulated and not absorbed at the external surface of the nanoparticles and that the shell of NLCs acted as a barrier to interfacial diffusion.

\section{Conclusions and further developments}

In this study, NLCs were prepared by hot high-pressure homogenization using a mixture of carnauba wax and isodecyl oleate. The method resulted in consistent production of smaller size nanoparticles in the range $200-300 \mathrm{~nm}$ with narrow size distribution (PI < 0.25). The surfactant (polysorbate 80 ) was optimized at $1 \%$ based on the particle size and polydispersity indices.

The current investigation illustrates the effect of the composition of the lipid mixture on the entrapment efficiency, in vitro release and stability of benzophenone-3-loaded in these NLCs. A loading capacity of approximately $5 \%$ of BZ-3 $\left(\mu \mathrm{g}_{\mathrm{BZ}-3} / \mathrm{mg}_{\text {lipids }}\right)$ was characteristic of these systems.

The physical stability of aqueous BZ-3-loaded nanosupensions was proven for at least 30 days. Previous data have shown that incorporation of NLCs or SLN in viscous gels or o/w creams leads to enhancement of physical stability, i.e, NLCs or SLN initially unstable in aqueous dispersion are now sufficiently stabilized. From this, it can be assumed that the NLCs developed in this study will lead to long-term stable sunscreen gels or creams. The next steps are to formulate gels/creams and test their sun protection efficiency.

\section{Acknowledgements}

The authors are grateful to CNPq (Brazilian Network of Nanocosmetics). The authors also thank Ms.Toshie Kawano and Mr. Alexsander Seixas de Souza (Laboratory of Parasitology and Malacology, Butantan Institute, Sao Paulo, SP, Brazil) for the CLSM analyses. The authors are grateful to the Brazilian National Research and Development Council (CNPq) and to the Brazilian Network of Nanocosmetics for financial support.

\section{References}

1. Muchow, M. (2009) Nanocarriers for oral bioavailability enhancement. (http://www. scd.uhp-nancy.fr/docnum/SCD_T_2009_0073_ MUCHOW.pdf) Accessed 10 August 2010.

2. Gulbake, A., Jain, A., Khare, P. and Jain, S.K. Solid lipid nanoparticles bearing oxybenzone: In-vitro and in-vivo evaluation. J. Microencapsul. 27, 226-233 (2010).

3. Müller, R.H., Petersen, R.D., Hommoss, A. and Pardeike, J. Nanostructured lipid carriers (NLC) in cosmetic dermal products. Adv. Drug. Del. Rev. 59, 522-530 (2007).

4. Pardeike, J., Hommoss, A. and Müller, R.H. Lipid Nanoparticles (SLN, NLC) in cosmetic and pharmaceutical dermal products. Int. J. Pharm. 366, 170-184 (2009).

5. Xia, Q., Saupe, A., Müller, R.H. and Souto, E.B. Nanostructured lipid carriers as novel carrier for sunscreen formulations. Int. J. Cosmet. Sci. 29, 473-482 (2007).

6. Wu, X. and Guy, R.H. Applications of nanoparticles in topical drug delivery and in cosmetics. J. Drug Deliv. Sci. Technol. 19, 371384 (2009).

7. Lacatusu, I., Badea, N., Murariu, A., Bojin, D. and Meghea, A. Effect of UV sunscreens loaded in solid lipid nanoparticles: a combinated SPF assay and photostability. Mol. Cryst. Liq. Cryst. 523, 247-259 (2010).

8. Yuan, H., Wang, L.-L., Du, Y.-Z., You, J., Hu, F.-Q. and Zeng, S. Preparation and characteristics of nanostructured lipid carriers for control-releasing progesterone by melt-emulsification. Coll. Surf. B: Bioint. 60, 174-179 (2007).

9. Teeranachaideekul, V., Souto, E.B., Junyaprasert, V.B. and Müller, R.H. Cetyl palmitate-based NLC for topical delivery of
Coenzyme $Q_{10}$ - Development, physicochemical characterization and in vitro release studies. Eur. J. Pharm. Biopharm. 67, 141148 (2007).

10. Souto, E.B., Wissing, S.A., Barbosa, C.M and Müller, R.H. Evaluation of the physical stability of SLN and NLC before and after incorporation into hydrogel formulations. Eur. J. Pharm. Biopharm. 58, 83-90 (2004).

11. Bodmeier, R.A. Waxes. In: Encyclopedia Pharmaceutical Technology (Swarbrick, J., ed.), pp. 2988-2999. Marcel Dekker, New York, NY (2002).

12. CERAPHYL® 140A. V. Description. Cognis Care Chemicalls Bull, 2002.

13. Villalobos-Hernández, J.R. and Müller-Goymann, C.C. Physical stability, centrifugation tests, and entrapment efficiency studies of carnauba wax-decyl oleate nanoparticles used for the dispersion of inorganic sunsc- 
reens in aqueous media. Eur. J. Pharm. Biopharm. 63, 115-127 (2006).

14. Villalobos-Hernández, J.R. and Müller-Goymann, C.C. Novel nanoparticulate carrier systems based on carnauba wax an decyl oleate for the dispersion of inorganic sunscreens in aqueous media. Eur. J. Pharm. Biopharm. 60, 113-122 (2005).

15. Villalobos-Hernández, J.R. and Müller-Goymann, C.C. In vitro erythemal UV-A protection factors of inorganic sunscreens distributed in aqueous media using carnauba wax-decyl oleate nanoparticles. Eur. J. Pharm. Biopharm. 65, 122-125 (2007).

16. Nesseem, D. Formulation of sunscreens with enhancement sun protection factor response based on solid lipid nanoparticles. Int J Cosmet Sci. (2010) [Epub ahead of print].

17. Weiner, N. Introduction. In: Pharmaceutical Dosage Forms: Disperse Systems, Vol. 1, (Liebermann, H.A., Rieger, M.M. and Banker, S., eds), pp. 1-14. Marcel Dekker, New York, NY (1996).

18. Grimm, W. General concept of stability testing. In: Stability Testing in the EC, Japan and USA (Grimm, W. and Krummen, K., eds.), pp. 191-223. Wissenschaftliche, Verlagsgesellschaft mbH, Stuttgart, Germany, (1984).

19. Müller, R.H., Mäder, K. and Gohla, S. Solid lipid nanoparticles for controlled delivery - a review of the state of art. Eur. J. Pharm. Biopharm. 50, 161-177 (2000).
20. Sarveiya, V., Risk, S. and Benson, H.A.E. Liquid chromatographic assay for common sunscreen agents: application to in vivo assessment of skin penetration and systemic absorption in human volunteers. J. Chromat. B. 803, 225-231 (2004).

21. Paese, P. Desenvolvimento Tecnológico, estudo de fotoestabilidade e avaliação da permeação cutânea in vitro da benzofenona-3 a partir de nanocápsulas poliméricas incorporadas em diferentes veículos semi-sólidos. 213f. Programa de Pós Graduação em Ciências Farmacêuticas. Faculdade de Farmácia. Universidade Federal do Rio Grande do Sul, Porto Alegre (2008).

22. de Vringer, T. and de Ronde, H.A. Preparation and structure of a water-in-oil cream containing lipid nanoparticles. J. Pharm. Sci. 84, 466-472 (1995).

23. Petzold, G., Dutschk, V., Mende, M. and Miller, R. Interaction of cationic surfactant and anionic polyelectrolytes in mixed aqueous solutions. Coll. Surf. A: Phys. Engin. Asp. 319, 43-50 (2008).

24. Pardeike, J. and Müller, R.H. Penetration Enhancement and Occlusion Properties of Coenzyme Q10-loaded NLC. The Am. Assoc Pharm Sci.(AAPS), San Antonio, Texas (2006).

25. Müller, R.H., R Petersen, D., Hommoss, A. and Pardeike, J. Nanostructured lipid carriers (NLC) in cosmetic dermal products. Adv. Drug Del. Reviews 84, 522-530 (2007).
26. Souto, E.B. and Müller, R.H. Cosmetic Features and applications of lipid nanoparticles (SLN, NLC). Int. J. Cosm. Sci. 30, 157-165 (2008).

27. Teeranachaideekul, V., Boonme, P., Souto, E., Müller, R.H. and Junyaprasert, V.B. Influence of oil content on physicochemical properties and skin distribution of Nilered-loaded NLC. J. Cont. Rel. 128, 134-141 (2008).

28. Borgia, S.L., Regehly, M., Sivaramakrishnan, R. et al. Lipid nanoparticles for skin penetration enhancement - correlation to drug localization within the particle matrix as determined by fluorescence and parelectric spectroscopy. J. Cont. Rel. 110, 151-163 (2005).

29. Lee, K.-H., Chen, S.-J., Jeng, J.-Y., Cheng, Y.C., Shiea, J.-T. and Chang, H.-T. Fluorescence and interactions with thiol compounds of Nile Red-adsorbed gold nanoparticles. J.Coll. Interf. Sci. 307, 340348 (2007).

30. Schaffazick, S.R. and Guterrez, S.S. Caracterização e estabilidade fisico-quimica de sistemas poliméricos nanoparticulados para administração de fármacos. Quím. Nova. 26. 726-737 (2003).

31. Muller, R.H., Mehnert, W., Lucks, W. and Schwarz, J.S. Solid lipid nanoparticles (SLN) - an alternative colloidal carrier system for controlled drug delivery. Eur. J. Pharm. Biopharm. 41, 423-427 (2002). 